\title{
Toward a Unified Treatment of Electronic Processes in Organic Semiconductors
}

Conference Paper NREL/CP-590-37617 January 2005

\section{B.A. Gregg}

Presented at the 2004 DOE Solar Energy Technologies Program Review Meeting October 25-28, 2004 Denver, Colorado

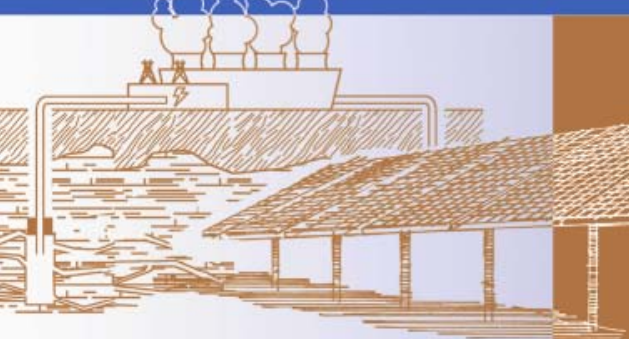




\section{NOTICE}

The submitted manuscript has been offered by an employee of the Midwest Research Institute (MRI), a contractor of the US Government under Contract No. DE-AC36-99G010337. Accordingly, the US Government and MRI retain a nonexclusive royalty-free license to publish or reproduce the published form of this contribution, or allow others to do so, for US Government purposes.

This report was prepared as an account of work sponsored by an agency of the United States government. Neither the United States government nor any agency thereof, nor any of their employees, makes any warranty, express or implied, or assumes any legal liability or responsibility for the accuracy, completeness, or usefulness of any information, apparatus, product, or process disclosed, or represents that its use would not infringe privately owned rights. Reference herein to any specific commercial product, process, or service by trade name, trademark, manufacturer, or otherwise does not necessarily constitute or imply its endorsement, recommendation, or favoring by the United States government or any agency thereof. The views and opinions of authors expressed herein do not necessarily state or reflect those of the United States government or any agency thereof.

Available electronically at http://www.osti.gov/bridge

Available for a processing fee to U.S. Department of Energy and its contractors, in paper, from:

U.S. Department of Energy

Office of Scientific and Technical Information

P.O. Box 62

Oak Ridge, TN 37831-0062

phone: 865.576.8401

fax: 865.576 .5728

email: mailto:reports@adonis.osti.gov

Available for sale to the public, in paper, from:

U.S. Department of Commerce

National Technical Information Service

5285 Port Royal Road

Springfield, VA 22161

phone: 800.553 .6847

fax: 703.605.6900

email: orders@ntis.fedworld.gov

online ordering: http://www.ntis.gov/ordering.htm

Printed on paper containing at least $50 \%$ wastepaper, including $20 \%$ postconsumer waste 


\title{
Toward a Unified Treatment of Electronic Processes in Organic Semiconductors
}

\author{
Brian A. Gregg \\ National Renewable Energy Laboratory \\ 1617 Cole Boulevard, Golden, Colorado 80401, brian_gregg@nrel.gov
}

\begin{abstract}
A quantitative study of n-type doping in highly crystalline organic semiconductor films establishes the predominant influence of electrostatic forces in these lowdielectric materials. Based on these findings, a selfconsistent model of doped (purposely or not) organic semiconductors is proposed in which: 1) the equilibrium free carrier density, $n_{f}$, is a small fraction of the total charge density; 2) a superlinear increase in conductivity with doping density is universal; 3) $n_{f}$ increases with applied electric field; and 4) the carrier mobility is field-dependent regardless of crystallinity.
\end{abstract}

\section{Introduction}

No self-consistent treatment of excitonic processes, doping and carrier transport in organic semiconductors is yet available. There are existing models for the individual processes, but the assumptions made to model one process can be incompatible with those made to model another. Here we show that all these processes are controlled by the same factors, primarily electrostatic forces and the spatial extent of the charge carrier wavefunctions, and thereby provide a unified conceptual foundation upon which more detailed models can be based. The factors that lead to excitonic behavior are quite fundamental[1,2] and affect many characteristics of the material, not just the photogeneration process. We briefly describe the origin of excitonic behavior, doping processes in organic semiconductors, the native carrier density in XSCs and its relation to purposely doped materials and finally, the expected field-dependence of both the free carrier density, $n_{f}$, and the carrier mobility, $\mu$.

\section{Excitonic Semiconductors}

In a semiconductor with hydrogen-like wavefunctions (such as silicon), the Bohr radius of the electronic state is estimated to be

$$
r_{B}=r_{0} n^{2} \varepsilon\left(m_{e} / m_{e f f}\right)
$$

where $r_{0}$ is the first Bohr radius of an electron in a hydrogen atom, $n$ is the quantum number of the orbital, $m_{e}$ is the mass of a free electron in vacuum and $m_{\text {eff }}$ is the effective mass of the electron in the semiconductor. A charge carrier becomes free from its electrostatic attraction to an opposite charge at $r_{c}$, the critical distance between the two charges,

$$
r_{C}=\left(q^{2} / 4 \pi \varepsilon \varepsilon_{0} k_{B} T\right),
$$

where $q$ is the electronic charge and $\varepsilon_{0}$ is the permittivity of free space.
Excitonic behavior is observed if $r_{C}>r_{B}$. We define a quantity, $\gamma$, that approximately distinguishes between conventional and excitonic semiconductors:

$$
\begin{aligned}
& \gamma=\frac{r_{c}}{r_{B}} \approx\left(\frac{q^{2}}{4 \pi n^{2} \varepsilon_{o} k_{B} r_{o} m_{e}}\right)\left(\frac{m_{\text {eff }}}{\varepsilon^{2} T}\right) \\
& \gamma>1: \quad \text { Excitonic semiconductor, XSC } \\
& \gamma<1: \quad \text { Conventional semiconductor, CSC }
\end{aligned}
$$

Equation 3 is only a rough approximation for several reasons which will be discussed. Note that CSCs become excitonic at low $T$, and therefore can provide a relevant comparison to organic XSCs at room temperature. A schematic representation of the factors described in eq. 3 is shown in Figure 1.

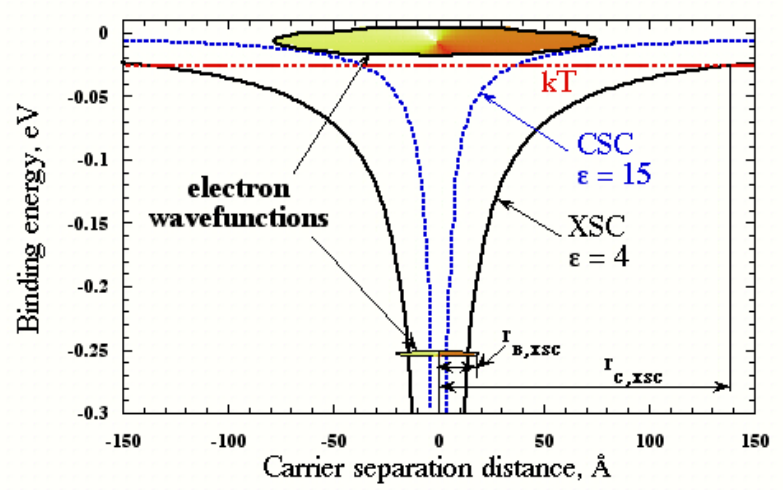

Figure 1. A schematic of the most fundamental differences between CSCs and XSCs showing $r_{B}$ and $r_{C}$ for XSCs. This general scheme applies to all electrostatic attractions in the semiconductor, not just to photogenerated carriers.

\section{Doping}

The conductivity of doped XSC films increases superlinearly with increasing dopant concentration, $n_{d}$, in all quantitative studies of doping in monomeric and polymeric XSCs of which we are aware. A simple model based on the factors contained in $\gamma$ can explain the apparent universality of this superlinear increase in conductivity with doping density in XSCs.[3]

Pearson and Bardeen first reported that the activation energy for free carrier production, $E_{a}$, in doped silicon decreases with increasing dopant concentration at low temperature. The low dielectric constant and the small Bohr radii that are characteristic of XSCs (Fig. 1, $\gamma>1$ ) typically result in $E_{a, \max }$ of hundreds of $\mathrm{meV}$. Therefore, $E_{a}$ is expected to control $n_{f}$ in XSCs even at room temperature. This fact can explain much of the electrical behavior of XSCs. We attribute the superlinear increase in $\sigma$ with $n_{d}$ to the increasing polarizability of the film caused by addition 
of polarizable dopants:[3] Identical effects should occur in nominally undoped, but charged-defect-rich materials such as $\pi$-conjugated polymers.

In many nominally undoped XSCs, the total equilibrium charge density may be far larger than expected. Defect carrier generation may be especially prominent in $\pi$ conjugated polymers because their conducting backbone consists of a semi-infinite chain of high-energy covalent $\pi$ bonds. The inevitable twists and bends in the backbone of these quasi-amorphous polymer films produce a high density of electronic states in the bandgap, some of which will be charged. Many XSCs, especially those with such "covalent disorder" are adventitiously doped to such a high level that their electronic behavior resembles that of purposely doped molecular XSCs.

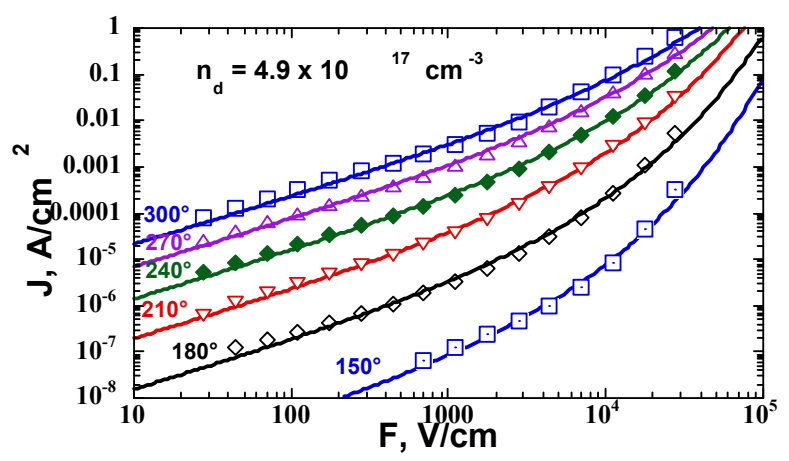

Figure 2. Typical $J-F$ curves versus temperature for a polycrystalline film doped to $n_{\mathrm{d}}=4.9 \times 10^{17} \mathrm{~cm}^{-3}$.

\section{Transport}

The same spatial and electrostatic considerations that cause exciton formation, and cause most added dopant electrons to remain bound near their conjugate dopant counterions in XSCs, also effect carrier transport by controlling $n_{f}$. The Poole-Frenkel (PF) mechanism treats the effect of $F$ on the number of carriers trapped in Coulomb potential wells in an isotropic solid and, therefore, describes also the current density, $J$. We expect this mechanism (modified by a field-dependent mobility) to semiquantitatively describe the $J-F$ characteristics of many purposely and adventitiously doped XSCs. Figure 2 shows typical J-F curves of a liquid crystalline perylene diimide doped n-type to a density of $n_{\mathrm{d}}=4.9 \times 10^{17} \mathrm{~cm}^{-3}$. The fits are to a modified PF equation.

The mobility of charge carriers in XSCs usually increases with increasing electric field. This process is formally independent of the field-assisted increase in $n_{f}$ (e.g., the PF mechanism) although in practice, $n_{f}$ and $\mu$ are often coupled. The existence of a substantial density of bound charges in doped (purposely or not) XSCs causes spatial fluctuations in the conduction and valence band energies. These dipoles decrease the carrier mobilities relative to the "flat band" case. Nominally undoped $\pi$ conjugated polymers, and other defect-rich XSCs, are expected, therefore, to have a large dipole density resulting in a field-dependent carrier mobility.

\section{Summary}

We propose a general organizing principle, $\gamma$ (eq. 3), that approximately distinguishes between XSCs and CSCs. It is a function of dielectric constant, the spatial delocalization of the carrier wavefunction, $r_{B}$, temperature, etc. Light absorption by an XSC leads to electrostatically bound electron-hole pairs (excitons). Doping an XSC ntype leads primarily to electrons bound to their conjugate dopant ions. The number of free electrons increases with increasing dielectric constant and with increasing electric field. The mobility of the electrons is diminished and becomes field dependent whenever $r_{B}$ is smaller than the spatial potential fluctuations.

\section{ACKNOWLEDGEMENTS}

I am grateful to the U.S. DOE, Office of Science, Division of Basic Energy Sciences, Chemical Sciences Division for supporting this research.

\section{REFERENCES}

[1] Gregg, B. A.; Hanna, M. C. J. Appl. Phys. 2003, 93, 3605 .

[2] Gregg, B. A. J. Phys. Chem. B 2003, 107, 4688.

[3] Gregg, B. A.; Chen, S.-G.; Branz, H. M. Appl. Phys. Lett. 2004, 84, 1707. 


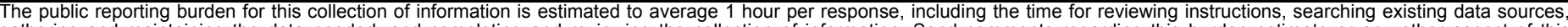

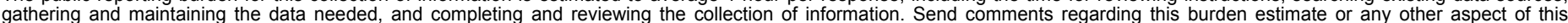

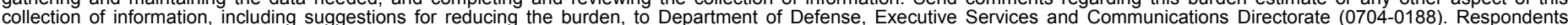

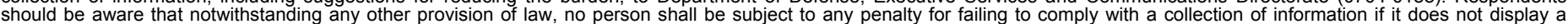

should be aware that notwithstanding

PLEASE DO NOT RETURN YOUR FORM TO THE ABOVE ORGANIZATION.

\begin{tabular}{l|l|l|l} 
1. REPORT DATE $(D D-M M-Y Y Y Y)$ & 2. REPORT TYPE & 3. DATES COVERED (FrOm - TO)
\end{tabular} January 2005

Conference Paper

4. TITLE AND SUBTITLE

Toward a Unified Treatment of Electronic Processes in Organic Semiconductors 5a. CONTRACT NUMBER

DE-AC36-99-G010337

5b. GRANT NUMBER

5c. PROGRAM ELEMENT NUMBER

5d. PROJECT NUMBER

NREL/CP-590-37617

5e. TASK NUMBER

5f. WORK UNIT NUMBER

7. PERFORMING ORGANIZATION NAME(S) AND ADDRESS(ES)

National Renewable Energy Laboratory

1617 Cole Blvd.

Golden, CO 80401-3393

9. SPONSORING/MONITORING AGENCY NAME(S) AND ADDRESS(ES)
8. PERFORMING ORGANIZATION REPORT NUMBER

NREL/CP-590-37617
10. SPONSOR/MONITOR'S ACRONYM(S) NREL

11. SPONSORING/MONITORING AGENCY REPORT NUMBER

12. DISTRIBUTION AVAILABILITY STATEMENT

National Technical Information Service

U.S. Department of Commerce

5285 Port Royal Road

Springfield, VA 22161

13. SUPPLEMENTARY NOTES

14. ABSTRACT (Maximum 200 Words)

A quantitative study of n-type doping in highly crystalline organic semiconductor films establishes the predominant influence of electrostatic forces in these low-dielectric materials. Based on these findings, a self-consistent model of doped (purposely or not) organic semiconductors is proposed in which: 1) the equilibrium free carrier density, $n_{f}$, is a small fraction of the total charge density; 2) a superlinear increase in conductivity with doping density is universal; 3) $n_{f}$ increases with applied electric field; and 4) the carrier mobility is field-dependent regardless of crystallinity.

15. SUBJECT TERMS

PV; n-type doping; crystalline; organic semiconductor films; electrostatic forces; carrier density; wavefunction; electron-hole pairs (excitons);

\begin{tabular}{|c|c|c|c|c|}
\hline \multicolumn{3}{|c|}{ 16. SECURITY CLASSIFICATION OF: } & \multirow{2}{*}{$\begin{array}{l}\text { 17. LIMITATION } \\
\text { OF ABSTRACT } \\
\text { UL }\end{array}$} & \multirow{2}{*}{$\begin{array}{l}\text { 18. NUMBER } \\
\text { OF PAGES }\end{array}$} \\
\hline $\begin{array}{l}\text { a. REPORT } \\
\text { Unclassified }\end{array}$ & $\begin{array}{l}\text { b. ABSTRACT } \\
\text { Unclassified }\end{array}$ & $\begin{array}{l}\text { c. THIS PAGE } \\
\text { Unclassified }\end{array}$ & & \\
\hline
\end{tabular}

19a. NAME OF RESPONSIBLE PERSON

19b. TELEPHONE NUMBER (Include area code) 